\title{
Endovascular Treatment of a Partially Thrombosed Giant Basilar Tip Aneurysm Using Interlocking Detachable Coils -Case Report-
}

\author{
Keiko IRIE, Waro TAKI, Ichiro NAKAHARA, Nobuyuki SAKAI, \\ Fumiaki ISAKA, and Haruhiko KIKUCHI
}

Department of Neurosurgery, Faculty of Medicine, Kyoto University, Kyoto

\begin{abstract}
A 65-year-old female presented with visual acuity loss. Magnetic resonance imaging confirmed the presence of a partially thrombosed giant aneurysm on the basilar tip. Cerebral angiography showed the opacified lumen of the aneurysm was $25 \times 15 \mathrm{~mm}$ with a broad-based neck. Using a transfemoral approach, a microcatheter was guided through the vertebral artery and placed directly into the aneurysm under local anesthesia. Interlocking detachable coils were deposited into the patent portion of the aneurysm, resulting in $95 \%$ obliteration of the aneurysm and preservation of the parent artery. No complication was observed during or after surgery. Follow-up angiography 2 months later demonstrated the aneurysm was 95\% occluded. No coil compaction was observed. Endovascular coil embolization therapy provides a therapeutic option for management of basilar tip aneurysms.
\end{abstract}

Key words: endovascular surgery, interlocking detachable coil, aneurysm, basilar tip

\section{Introduction}

Aneurysms of the posterior circulation are more difficult to treat and have a worse surgical outcome than those arising in the anterior circulation. ${ }^{11)}$ In particular, aneurysms at the basilar artery bifurcation are the most difficult cerebrovascular lesions for neurosurgeons to manage. The natural history of untreated giant aneurysms is associated with poor outcome, as mortality is up to $80 \%$ within several years. Giant aneurysms that were unruptured at presentation have a 2-year mortality rate of $62 \% .{ }^{15}$ ) The aim of neurosurgical therapy for cerebral aneurysms is to prevent rebleeding or rupture and to reduce the mass effect. The treatment of choice for intracranial aneurysms is surgical clipping. However, surgical treatment of basilar tip aneurysms is characterized by a high morbidity and mortality because of the deep location behind the posterior clinoids, the narrow operating field in the interpeduncular cistern, and their close anatomical relationship to vital brain stem perforation branches., ${ }^{3,10,14)}$ Recently, the placement of various types of plati- num coils within the lumen of the aneurysm has become possible..$^{2,4,5,12)}$

We described a patient with a partially thrombosed giant basilar tip aneurysm which was embolized using interlocking detachable coils (IDC).

\section{Case Report}

A 65-year-old female presented with loss of left visual acuity. Brain magnetic resonance imaging confirmed the presence of a partially thrombosed giant aneurysm on the basilar tip (Fig. 1). Cerebral angiography demonstrated that the opacified lumen of the aneurysm measured was $25 \times 15 \mathrm{~mm}$ with a broad-based neck (Fig. 2).

The aneurysm was treated by coil embolization using IDC (Target Therapeutics Inc., Fremont, Cal., U.S.A.). Under local inguinal lidocaine anesthesia, a 7.0 Fr guiding catheter was introduced into the left vertebral artery via the transfemoral approach. Heparin (4000 U) was then injected intravenously for systemic anticoagulation. A coaxial microcatheter (Fas Tracker $18 \mathrm{MX}$ catheter ${ }^{\circledR}$; Target Ther- 

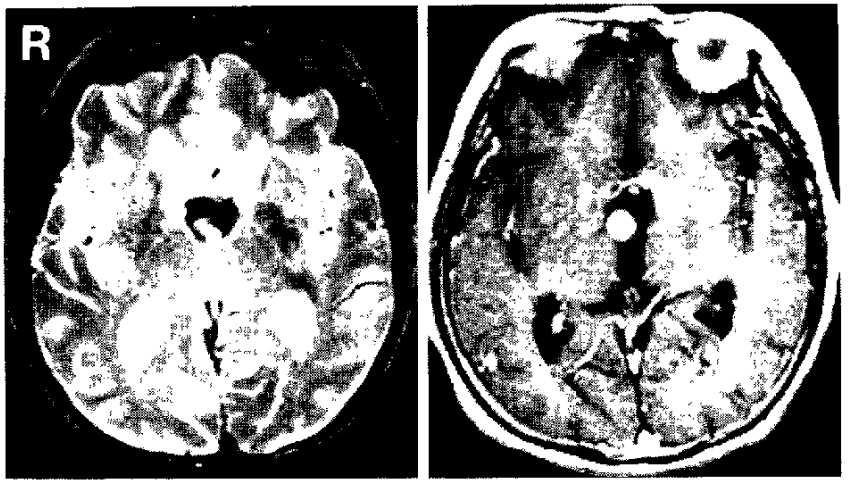

Fig. $1 T_{2}$-weighted magnetic resonance ( $M R$ ) image revealing a low intensity mass including an area of high intensity (left), and $T_{1}$-weighted MR image with gadolinium-diethylenetriaminepenta-acetic acid showing partial enhancement in the low intensity area (right).
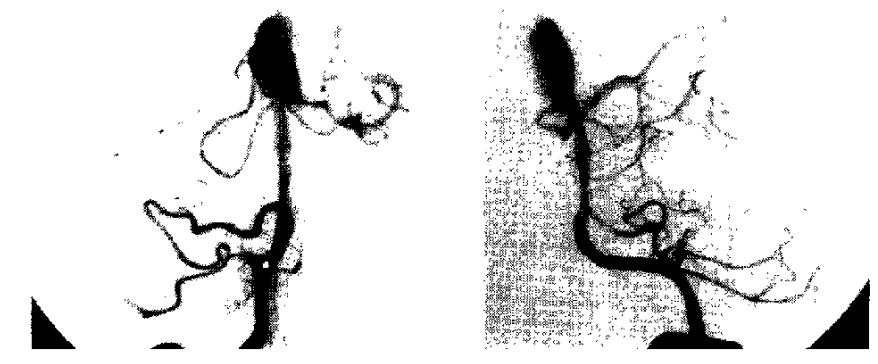

Fig. 2 Right vertebral angiograms, frontal (left) and lateral views (right), demonstrating the giant basilar tip aneurysm before embolization.

apeutics Inc.) introduced through the guiding catheter was passed under fluoroscopic guidance through the intracranial vertebral and basilar arteries and finally into the aneurysm. Angiography confirmed the catheter placement within the aneurysm lumen. Fourteen coils with a total length of $210 \mathrm{~cm}$ were placed in the aneurysm to achieve occlusion. Immediate post-embolization angiography showed the aneurysm to be approximately $95 \%$ occluded (Fig. 3). Systemic anticoagulation was then reversed with intravenous protamine sulfate.

Follow-up post-embolization angiography 2 months later demonstrated that the aneurysm was $95 \%$ occluded. There was no coil compaction observed. Her visual acuity loss disappeared 2 months after embolization.
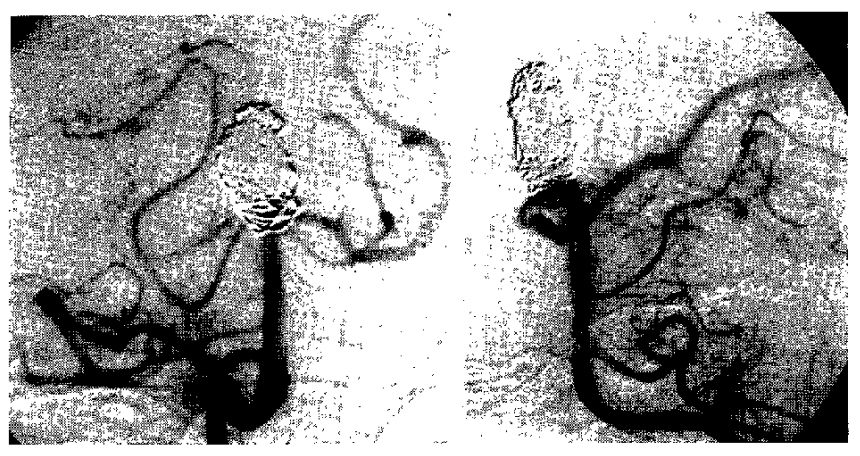

Fig. 3 Right vertebral angiograms, frontal (left) and Iateral views (right), demonstrating approximately $95 \%$ occlusion of the aneurysm following placement of platinum coils within the aneurysm.

\section{Discussion}

Endovascular treatment of aneurysms was initially based on using detachable balloons in 1974. ${ }^{16)}$ The new detachable balloon was used to occlude a giant aneurysm of the right middle cerebral artery in 1979. ${ }^{17}$ Endovascular treatment of 26 aneurysms in 25 patients with intra-aneurysm occlusion was previously limited to balloon embolization..$^{81}$ However, the balloons cannot adapt to the irregular shape of the aneurysm, and so stress on the aneurysm may occur during balloon placement and detachment, increasing the risk of aneurysm rupture.

Recently, the placement of soft metallic coils within the lumen of the aneurysm has become possible, using the Guglielmi detachable coils (Target Therapeutics Inc.). ${ }^{4-6)}$ These coils are based on the principle of electrothrombosis and allow more controlled coil placement and detachment. ${ }^{13,19)}$ The IDC used in the present study is detached mechanically. The proximal end of the platinum coil is connected to an introducing wire catheter by an interlocking junction. When the coil is pushed out of the catheter, the interlock is disconnected, and the coil is detached immediately. However, caution needs to be exercised since the position and structure of the coil may change before its release, causing continued stress on the aneurysm wall.

Embolization for the treatment of thrombotic aneurysm is controversial, because the coil can migrate into the intraluminal thrombus or blood flow, causing compacting of the coil and facilitating the patency of the aneurysm again. Little data has been published regarding the efficacy of endovascular occlusion on symptoms and signs relating to mass effect. $^{\text {.) }}$ The size of the aneurysm neck is well correlat- 
ed with the outcome of the endovascular treatment. Complete aneurysm occlusion was possible in $\mathbf{8 5 \%}$ of small-necked aneurysms but in only $15 \%$ of widenecked aneurysms. ${ }^{19}$ ) Large and giant aneurysms with a wide neck are difficult to treat by intraaneurysmal occlusion using detachable platinum coils. Platinum microcoils were successfully used in patients with intracranial aneurysms containing thrombus with a broad-based neck..$^{\text {g) }}$ The patients presented with cerebellar symptoms related to the mass effect of the aneurysm before surgery. However, follow-up angiography 4 months after embolization revealed obliteration of aneurysms, and the cerebellar symptoms had disappeared. Electrically detachable coils were used to treat 13 patients with basilar artery bifurcation aneurysms by electrothrombosis. ${ }^{1]}$ Two patients had presented mass effects, and in one of these, follow-up angiography 6 months after embolization revealed complete disappearance of the aneurysm, and an excellent outcome was achieved. Endovascular techniques were used to treat 13 aneurysms with mass effect, but improvement of neurological signs was achieved in only one patient who had improved visual acuity following therapy. ${ }^{18)}$

In our patient, endovascular management of a partially thrombosed giant basilar tip aneurysm was achieved using an IDC device. Almost complete occlusion of the aneurysm was achieved. Follow-up angiography after embolization showed an absence of coil compaction. Visual acuity loss caused by the mass effect of the aneurysm disappeared 2 months after embolization. There were no other complications. Only a few follow-up studies on aneurysmal coil embolization are available because of the relatively short history of this treatment. In the future, strict angiographic and long-term clinical follow-up is needed. Endovascular coil embolization therapy provides a therapeutic option for management of basilar tip aneurysms.

\section{References}

1) Bavinzski G, Richling B, Gruber A, Killer M, Levy D: Endovascular occlusion of basilar artery bifurcation aneurysms using electrically detachable coils. Acta Neurochir (Wien) 134: 184-189, 1995

2) Casasco AE, Aymard A, Gobin YP, Haudart E, Rogopoulos A, George B, Hodes JE, Cophignon J, Merland JJ: Selective endovascular treatment of 71 intracranial aneurysms with platinum coils. I Neurosurg 79: 3-10, 1993

3) Drake CG: Surgical treatment of ruptured aneurysms of the basilar artery. Experience with 14 cases. J Neurosurg 23: 457-473, 1965

4) Guglielmi G, Viñuela F, Dion J, Duckwiler G: Elec- trothrombosis of saccular aneurysm via endovascular approach. Part 2: Preliminary clinical experience. J Neurosurg 75: 8-14, 1991

5) Guglielmi G, Viñuela F, Duckwiler G, Dion J, Lylyk P, Berenstein A, Strother C, Graves V, Halbach V, Nichols D, Hopkins N, Ferguson R, Sepetka I: Endovascular treatment of posterior circulation aneurysms by electrothrombosis using electrically detachable coils. J Neurosurg 77: 515-524, 1992

6) Guglielmi G, Viñuela F, Sepetka I, Macellari V: Electrothrombosis of saccular aneurysms via endovascular approach. Part 1: Electrochemical basis, technique, and experimental results. J Neurosurg 75: 1-7, 1991

7) Halbach VV, Higashida RT, Dowd CF, Barnwell SL, Fraser KW, Smith TP, Teitelbaum GP, Hieshima GB: The efficacy of endosaccular aneurysm occlusion in alleviating neurological deficits produced by mass effect. J Neurosurg 80: 659-666, 1994

8) Higashida RT, Halbach VV, Cahan LR, Hieshima GB, Konishi Y: Detachable balloon embolization therapy of posterior circulation intracranial aneurysms. J Neurosurg 71: 512-519, 1989

9) Higashida RT, Halbach VV, Dowd CF, Barnwell SL, Hieshima GB: Interventional neurovascular treatment of a giant intracranial aneurysm using platinum microcoils. Surg Neurol 35: 64-68, 1990

10) Jamieson KG: Aneurysms of the vertebrobasilar system. Surgical intervention in 19 cases. J Neurosurg 21: 781-797, 1964

11) Kassell NF, Torner JC, Jane JA, Haley EC Jr, Adams HP, participants: The International Cooperative Study on the Timing of Aneurysm Surgery. Part 2: Surgical results. J Neurosurg 73: 37-47, 1990

12) Marks MP, Chee H, Liddell RP, Steinberg GK, Panahian N, Lane B: A mechanically detachable coil for the treatment of aneurysms and occlusion of blood vessels. AJNR Am J Neuroradiol 15: 821-827, 1994

13) McDougall CG, Halbach VV, Dowd CF, Higashida RT, Larsen DW, Hieshima GB: Endovascular treatment of basilar tip aneurysms using electrolytically detachable coils. J Neurosurg 84: 393-399, 1996

14) Peerless SJ, Drake CF: Management of aneurysms of posterior circulation, in Youmans JR (ed): Neurological Surgery, ed 2. Philadelphia, WB Saunders, 1982, pp 1715-1763

15) Peerless SJ, Wallace MC, Drake CG: Giant intracranial aneurysms, in Youmans JR (ed): Neurological Surgery, vol 7. Philadelphia, WB Saunders, 1990, pp 1742-1763

16) Serbinenko FA: Balloon catheterization and occlusion of major cerebral vessels. J Neurosurg 41: 125145, 1974

17) Taki $W$, Handa $H$, Yamagata $S$, Ishikawa $M$, Iwata $H$, Ikada Y: Balloon embolization of a giant aneurysm using a newly developed catheter. Surg Neurol 12: 363365,1979

18) Taki W, Nishi S, Yamashita $K$, Sadatoh A, Nakahara I, Kikuchi H, Iwata H: Selection and combination of 
various endovascular techniques in the treatment of giant aneurysms. $J$ Neurosurg 77: 37-42, 1992

19) Zubillage AF, Guglielmi G, Vinuela F, Duckwiler GR: Endovascular occlusion of intracranial aneurysms with electrically detachable coils: Correlation of aneurysm neck size and treatment results. AJNR Am J Neuroradiol 15: 815-820, 1994
Address reprint requests to: K. Irie, M.D., Department of Neurological Surgery, Kagawa Medical School, 1750-1 Ikenobe, Miki-cho, Kita-gun, Kagawa 76107, Japan. 